\title{
Comments on potential re-purposing of medicines against high-altitude illnesses towards SARS-CoV2: possibilities and pitfalls
}

\author{
Yasmin Ahmad ${ }^{1} \cdot$ Subhojit Paul ${ }^{1} \cdot$ Rajeev Varshney $^{1} \cdot$ Bhuvnesh Kumar $^{1}$ \\ Received: 8 October 2020 / Revised: 8 October 2020 / Accepted: 30 December 2020 / Published online: 20 January 2021 \\ (c) The Author(s), under exclusive licence to Springer Nature Singapore Pte Ltd. part of Springer Nature 2021
}

\begin{abstract}
In the ongoing COVID-19 pandemic, the global fraternity of researchers has been assiduously investigating pharmacological interventions against the SARS-CoV2. This novel virus is known to gain entry through the ACE 2 receptor of pulmonary epithelial cells lining the respiratory tract. Many of its initial symptoms (e.g. difficulty breathing) resemble acute high altitude illnesses, particularly HAPE. Based on these overt symptoms, a number of high altitude researchers have speculated on repurposing of drugs used to treat acute altitude illnesses (especially HAPE). However, eminent high altitude researchers with medical expertise as well as some studies on the deeper causes underlying the overt symptoms have found that such repurposing maybe counter-productive. Other factors, (e.g. contra-indications of these drugs), make their use in COVID-19 patients hazardous. The fit-for-repurposing options maybe experimental prophylactic interventions (e.g. silymarin, curcumin) which have proven anti-oxidant and anti-inflammatory effects. Another line of thought focuses on proteomics-based investigations of such patients. However, apart from the logistical and safety issues, a targeted proteomics approach based on prior sound molecular investigations is a more logical approach instead of mere shotgun proteomics. In this commentary, we shed light on such issues associated with COVID-19.
\end{abstract}

Keywords COVID $19 \cdot \mathrm{HAPE} \cdot$ Proteomics $\cdot$ Antioxidants

\section{Dear Editor,}

A lot of excitement and misplaced beliefs among the research fraternity, particularly a small group of high-altitude researchers, was observed in the recent past regarding the repurposing of drugs used in acute altitude illnesses (e.g. AMS, HAPE) towards late-stage SARS-CoV treatment. However, as more and more information has been unearthed about the same, we realise that except the knowledge of RAAS system being involved in SARS-CoV (ACE2 receptor is required for viral entry into epithelial cells of the respiratory tract (Groß et al. 2020)), not much is exactly known regarding how the virus interacts with the cells and the molecular events that underlie the clinical symptoms

Yasmin Ahmad

yasminchem@gmail.com

1 Defence Institute of Physiology and Allied Sciences (DIPAS), Defence R and D Organization (DRDO), Timarpur, New Delhi-110054, India evidenced by the high number of cell culture investigations using live virus and infected cells (Google scholar search terms "cell culture SARS coronavirus" and "SARS-COV cell culture" using the filter "since 2019" gave 2600 results in 0.08-0.14 s; accessed on 11th May 2020). Thus, the current situation demands patience till virologists and molecular biologists find out the molecular sequelae of coronaviruscell interaction.

With regard to the pandemic raging around the world, various groups have tried the hit and trial method with workable hypotheses to find cures, and quite logically so. But we are yet to find any drug that is proven to be effective. Multiple pharma/biotech companies (AstraZeneca, Pfizer, GSK, etc.) have made great strides towards a drug/ vaccine but they are yet to successfully clear the human trials. Our fraternity of high altitude researchers have also been proactive in this regard and we should pat ourselves on the back for the same. But recent investigations and careful observation by premier high altitude researchers (many with a background in Medicine) such as Budhha Basnyat, Andrew M Luks and Erik R Swenson have 
cautioned against equating apparent similarities between acute altitude illnesses and COVID symptoms (Brugger et al. 2020; Luks et al. 2020). We would like to tabulate their findings ${ }^{2}$ on the matter and leave the understanding to the readers.

\begin{tabular}{ll}
\hline HAPE & COVID \\
\hline Hypoxia causative & $\begin{array}{c}\text { Hypoxemia secondary to respira- } \\
\text { tory failure }\end{array}$ \\
No infectious agent & Transmitted viral disease \\
$\begin{array}{l}\text { Hypoxia-induced pulmonary } \\
\text { hypertension }\end{array}$ & $\begin{array}{c}\text { Pulmonary hypertension due to } \\
\text { multiple causes }\end{array}$ \\
Inflammatory factors secondary & $\begin{array}{l}\text { Primary alveolar-interstitial } \\
\text { Inflammation; intense host- } \\
\text { cytokine mediated response }\end{array}$ \\
Reversible with supplemental & Not reversible with oxygen alone \\
oxygen & Affects lung, kidney, heart, and \\
Affects only the lung & nervous system \\
No multi-organ system failure & Deaths from multi-organ system \\
& failure \\
Rarely pre-existing conditions & Common pre-existing conditions \\
worsen outcome & worsen outcome \\
Genetic susceptibility & Possible genetic susceptibility \\
Age independent & Increased mortality with increased \\
& age \\
\hline
\end{tabular}

(Adapted from Brugger H, Basnyat B, Ellerton J, Hefti U, Strapazzon G, Zafren K. COVID-19 Lung Injury Is Different From High Altitude Pulmonary Edema (Re: High Alt Med Biol [Epub ahead of print]; https://doi. org/10.1089/ham.2020.0055)).

We would also like to point out another relevant opinion (by Luks and Swenson (Luks and Swenson 2020)) and a critical original research article (by Huang et al. (Huang et al. 2020)) regarding the lack of similarities between COVID and acute altitude illnesses, particularly HAPE, before moving further.

Assuming the reader has read the abovementioned resources, it is imperative that proteomics and bioinformatics-based studies of infected patients be undertaken but only after the basic molecular mechanisms are clarified using cell culture investigations and animal model studies. In case the pandemic expands aggressively with higher mortality rates (should there be more viral mutations in store), we must investigate the infected patients using biofluid proteomics. However, a more targeted approach is recommended. Targeted proteomics is a much better option regarding an infectious disease instead of broadspectrum whole proteome studies without a sound molecular basis. Targeted proteomics may provide a clear basis of various proteins which may serve as therapeutic targets or markers. A suitable comparison would be healthy controls vs COVID-19 patients and recovered COVID-19 patients.
It might also be interesting to observe protein post-translational modifications (PTMs) in such groups as well as relevant epigenetic changes.

Even with drug repurposing, possible contra-indications and pitfalls of each drug should be carefully weighed against their speculated benefits in COVID-19 treatment. A popular high altitude drug is nifedipine, a calcium channel blocker. Its's known to rapidly relieve hypertension and angina. However, the fall in blood pressure can be unpredictable and rapid leading to ischemia. Its already contra-indicated in individuals with any cardiac, pulmonary, GI tract and hepatic issues. Its use is cautioned against in geriatric, diabetic and obese individuals (Khan et al. 2020). As is well known, most patients requiring emergency medical care due to SARS-CoV2 have some sort of pre-existing co-morbidities related to cardiac, pulmonary, metabolic and renal insufficiencies (Zhang et al. 2020; Du et al. 2020). Age by itself is a huge risk factor (Landi et al. 2020). Other similar drugs like acetazolamide, a diuretic, have also been proposed. However, this sulfonamide drug is contra-indicated in individuals with diabetes (type 1 and 2), decreased pulmonary, hepatic and renal capacities (Farzam and Abdullah 2020). Thus, it is amply clear that repurposing of drugs that help alleviate high altitude illnesses may be more of a dead end rather than a difficult road ahead.

However, in the case of prophylactics that were re-purposed for high altitude use (e.g. silymarin and curumin), the case might be the exact opposite. Silymarin was found to prevent lung damage in rodents exposed to simulated extreme altitude. This was due to its ROS-scavenging, antioxidant and anti-inflammatory effects (Paul et al. 2016; Aghazadeh et al. 2011). Since cytokine storm is a feature of late-stage COVID-19 patients (Pedersen and Ho 2020), silymarin can be a good treatment option. Curcumin, especially as nanocurcumin, with excellent immunostimulatory and anti-inflammatory properties (Aghazadeh et al. 2011; Mohajeri et al. 2015; Rahimi et al. 2016), may also help relieve the inflammatory after-effects of SARS-CoV2 in late-stage patients. Other similar prophylactics with little to no side-effects and contra-indications but considerable anti-oxidant and anti-inflammatory effects may also be tried on COVID-19 patients.

In view of the above, our personal opinion is to be slow and steady before embarking on any investigations regarding COVID treatments based on repurposed drugs and focusing on prior capacity building and infrastructural requirements. An important domain that is yet to be explored is the saliva/blood of recovered COVID patients as well as those who appear to have no symptoms/distress even with high viral load COVID. 


\section{Compliance with ethical standards}

Conflict of interest Authors state no conflict of interests.

\section{References}

Aghazadeh S, Amini R, Yazdanparast R, Ghaffari SH (2011) Exp Toxicol Pathol 63(6):569-574

Brugger H, Basnyat B, Ellerton J, Hefti U, Strapazzon G, Zafren K (2020) COVID-19 lung injury is different from high altitude pulmonary edema. High Alt Med Biol. https://doi.org/10.1089/ ham.2020.0061

Du R-H, Liang L-R, Yang C-Q, Wang W, Cao T-Z, Li M, Guo G-Y, Du J, Zheng C-L, Zhu Q (2020) Predictors of mortality for patients with COVID-19 pneumonia caused by SARS-CoV-2: a prospective cohort study. Eur Res J 55(5):2000524. https://doi. org/10.1183/13993003.00524-2020

Farzam K, Abdullah M (2020) Acetazolamide. In StatPearls, Treasure Island (FL)

Groß S, Jahn C, Cushman S, Bär C, Thum T (2020) SARS-CoV-2 receptor ACE2-dependent implications on the cardiovascular system: From basic science to clinical implications. J Mol Cell Cardiol 144:47-53. https://doi.org/10.1016/j.yjmcc.2020.04.031

Huang C, Wang Y, Li X, Ren L, Zhao J, Hu Y, Zhang L, Fan G, Xu J, Gu X (2020) Clinical features of patients infected with 2019 novel corona virus in Wuhan, China. Lancet 395(10223):497-506

Khan KM, Patel J, Schaefer TJ (2020) Nifedipine. In StatPearls, Treasure Island (FL)

Landi F, Barillaro C, Bellieni A, Brandi V, Carfî A, D’Angelo M, Fusco D, Landi G, Monaco RL, Martone A (2020) Frailty and COVID19: A Systematic Scoping Review. J Nutr Health Aging. https:// doi.org/10.3390/jcm 9072106
Luks AM, Swenson ER (2020) COVID-19 lung injury and high altitude pulmonary edema: a False equation with dangerous implications. Ann Am Thorac Soc. https://doi.org/10.1513/AnnalsATS.20200 4-327FR

Luks AM, Freer L, Grissom CK, McIntosh SE, Schoene RB, Swenson ER, Hackett PH (2020) COVID-19 lung injury is not high altitude pulmonary edema. High Altitude Med Biol 21(2):192-193. https ://doi.org/10.1089/ham.2020.0055

Mohajeri M, Sadeghizadeh M, Najafi F, Javan M (2015) Polymerized nano-curcumin attenuates neurological symptoms in EAE model of multiple sclerosis through down regulation of inflammatory and oxidative processes and enhancing neuroprotection and myelin repair. Neuropharmacology 99:156-167

Paul S, Arya A, Gangwar A, Bhargava K, Ahmad Y (2016) Size restricted silymarin suspension evokes integrated adaptive response against acute hypoxia exposure in rat lung. Free Radical Biol Med 96:139-151

Pedersen SF, Ho Y-C (2020) SARS-CoV-2: a storm is raging. J Clin Investig 130(5):2202-2205. https://doi.org/10.1172/JCI137647

Rahimi HR, Mohammadpour AH, Dastani M, Jaafari MR, Abnous K, Mobarhan MG, Oskuee RK (2016) The effect of nano-curcumin on $\mathrm{HbA1c}$, fasting blood glucose, and lipid profile in diabetic subjects: a randomized clinical trial. Avicenna J Phytomed 6(5):567

Zhang J-J, Dong X, Cao Y-Y, Yuan Y-D, Yang Y-B, Yan Y-Q, Akdis CA, Gao Y-D (2020) Clinical characteristics of 140 patients infected with SARS-CoV-2 in Wuhan, China. Allergy 75(7):17301741. https://doi.org/10.1111/all.14238

Publisher's Note Springer Nature remains neutral with regard to jurisdictional claims in published maps and institutional affiliations. 